\title{
Placental Responses to Changes in the Maternal Environment Determine Fetal Growth
}

\author{
Kris Genelyn Dimasuay ${ }^{1,2,3}$, Philippe Boeuf ${ }^{1,2,4}$, Theresa L. Powell ${ }^{3,5}$ and \\ Thomas Jansson ${ }^{3 *}$ \\ ${ }^{1}$ Department of Medicine, The University of Melbourne, Melbourne, VIC, Australia, ${ }^{2}$ Centre for Biomedical Research, Burnet \\ Institute, Melbourne, VIC, Australia, ${ }^{3}$ Department of Obstetrics and Gynecology, University of Colorado Anschutz Medical \\ Campus, Aurora, CO, USA, ${ }^{4}$ Victorian Infectious Diseases Service, Royal Melbourne Hospital, Melbourne, VIC, Australia, \\ ${ }^{5}$ Department of Pediatrics, University of Colorado Anschutz Medical Campus, Aurora, CO, USA
}

\section{OPEN ACCESS}

Edited by:

Carlos Alonso Escudero,

Universidad del Bio Bio, Chile

Reviewed by:

Keshari Thakali,

Arkansas Children's Nutrition Center,

USA

Loren P. Thompson,

University of Maryland, Baltimore,

USA

Marcelo Gonzalez,

Universidad de Concepcion, Chile

*Correspondence:

Thomas Jansson

thomas.jansson@ucdenver.edu

Specialty section: This article was submitted to

Vascular Physiology,

a section of the journal

Frontiers in Physiology

Received: 12 November 2015 Accepted: 11 January 2016

Published: 29 January 2016

Citation:

Dimasuay KG, Boeuf P, Powell TL and Jansson T (2016) Placental

Responses to Changes in the

Maternal Environment Determine Fetal

Growth. Front. Physiol. 7:12.

doi: 10.3389/fphys.2016.00012
Placental responses to maternal perturbations are complex and remain poorly understood. Altered maternal environment during pregnancy such as hypoxia, stress, obesity, diabetes, toxins, altered nutrition, inflammation, and reduced utero-placental blood flow may influence fetal development, which can predispose to diseases later in life. The placenta being a metabolically active tissue responds to these perturbations by regulating the fetal supply of nutrients and oxygen and secretion of hormones into the maternal and fetal circulation. We have proposed that placental nutrient sensing integrates maternal and fetal nutritional cues with information from intrinsic nutrient sensing signaling pathways to balance fetal demand with the ability of the mother to support pregnancy by regulating maternal physiology, placental growth, and placental nutrient transport. Emerging evidence suggests that the nutrient-sensing signaling pathway mechanistic target of rapamycin (mTOR) plays a central role in this process. Thus, placental nutrient sensing plays a critical role in modulating maternal-fetal resource allocation, thereby affecting fetal growth and the life-long health of the fetus.

Keywords: placental nutrient sensing, maternal-fetal exchange, mechanistic target of rapamycin, fetal programming, syncytiotrophoblast, pregnancy

\section{INTRODUCTION}

Adverse maternal influences in pregnancy are linked to alterations in the intrauterine milieu, which are associated with short-term complications including altered fetal growth and increased perinatal morbidity, as well as long-term adverse consequences for the health of the offspring. This concept of fetal programming or developmental origins of health and disease (Forsdahl, 1977; Barker and Osmond, 1986; Barker et al., 1989; Hales et al., 1991; Ravelli et al., 1998; Armitage et al., 2004; Gluckman and Hanson, 2004) suggests that successful prevention of adult metabolic disease relies on interventions during pregnancy.

The placenta senses and responds to changes in the maternal environment by altering its structure and function, which can lead to changes in blood flow, fetal nutrient supply, and secretion of hormones and other signaling molecules. Changes in transplacental nutrient transport may influence fetal nutrient availability, which determines fetal growth and body composition, and thus may link maternal perturbations to fetal programming.

The mechanisms by which altered maternal environment during pregnancy may lead to disease in the offspring are poorly understood. Here, we discuss maternal circulating factors that 
regulate placental function and highlight the role of placental mechanistic target of rapamycin (mTOR) signaling as a placental nutrient sensing signaling pathway that modifies placental nutrient transport in response to a multitude of factors.

\section{PLACENTAL NUTRIENT SENSING}

The placental nutrient sensing model proposes that the syncytiotrophoblast integrates maternal and fetal signals to regulate placental function. The model emphasizes the importance of changes in the maternal compartment (Gaccioli et al., 2013; Jansson and Powell, 2013) to which the placenta responds by matching fetal growth with the ability of the maternal supply line to allocate resources to the fetus. Maternal signals that provide information to the placenta may include metabolic hormones, nutrients levels, and oxygen. In conditions of compromised ability of the maternal supply line to deliver nutrients and oxygen to the placenta, placental functions including transplacental nutrient transport and placental growth, may be inhibited, directly contributing to decreased fetal growth. In contrast, in conditions of over-nutrition, placental nutrient sensing may lead to enhanced placental function, directly contributing to fetal overgrowth (Figure 1).

\section{THE PLACENTAL BARRIER}

The syncytiotrophoblast, the transporting and hormoneproducing epithelium of the placenta, constitutes the primary barrier for maternal-fetal exchange. The syncytiotrophoblast is a polarized epithelium with a maternal-facing microvillous plasma membrane (MVM) and a fetal-facing basal plasma membrane (BM). MVM and BM have distinct biological characteristics including different membrane composition and their expression of nutrient transporters. The expression and function of these nutrient transporters influence the placental capacity to transfer nutrients from the mother to the fetus, an important determinant of fetal growth.

Maternal factors including hormones, growth factors, and some cytokines have been shown to regulate transplacental nutrient transport. Insulin (Jansson et al., 2003; Roos et al., 2009), insulin-like growth factor I (IGF-I; Fang et al., 1997; Roos et al., 2009), leptin (Jansson et al., 2003), interleukin-6 (IL-6; Jones et al., 2009a), and tumor necrosis factor alpha (TNF- $\alpha$; Jones et al., 2007) positively regulate system A, a transport system that mediates non-essential neutral amino acid (AA) uptake. Receptors for numerous hormones, including IGF-I, insulin, and leptin are also present in the MVM (Desoye et al., 1994; Fang et al., 1997; Ebenbichler et al., 2002) suggesting that maternal hormones regulate trophoblast function. Concentrations of maternal serum IGF-I (Holmes et al., 1997) and leptin (Yildiz et al., 2002) are decreased in intrauterine growth restriction (IUGR) while pregnancies associated with obesity and diabetes have higher maternal serum IGF-I, insulin, and leptin (Lauszus et al., 2001; Jansson et al., 2008). This suggests that maternal factors can regulate the activity and expression of transporter proteins in the syncytiotrophoblast, which may influence fetal growth and health.

\section{DIVERSE MATERNAL SIGNALS IMPINGE ON THE PLACENTA}

A wide range of maternal factors impinges on the placenta, providing critical information about the ability of the maternal supply line to support pregnancy (Jansson et al., 2012; Gaccioli et al., 2013; Jansson and Powell, 2013; Díaz et al., 2014).

\section{Utero-Placental Blood Flow}

The development of certain pregnancy complications, particularly IUGR and preeclampsia, is associated with impaired utero-placental blood flow. Impaired utero-placental blood flow could cause "placental insufficiency", i.e., impaired nutrient and oxygen supply to the fetus. Placental insufficiency is often assumed to be due only to a reduced placental blood flow (Krishna and Bhalerao, 2011). However, the placental blood flow reduction per se does not adequately explain the impaired placental transfer in IUGR. For example, the primary limiting factor for the transplacental transport of nutrients such as glucose and AAs is their transport across the syncytiotrophoblast. We have proposed that the placenta senses the decreased blood flow or possibly hypoxia, and responds by down-regulating key placental nutrient transporters, directly contributing to IUGR. Moreover, the IUGR placenta has reduced intervillous space volume, poorly developed peripheral villi and thicker trophoblastic epithelium that decrease the nutrient exchange area and compromise the exchange functions of the placenta (Burton, 2010).

Animal models of impaired utero-placental blood flow show decreased placental nutrient transport capacity. Transplacental transport of glucose and AAs was decreased in IUGR following uterine artery ligation in the rat (Nitzan et al., 1979), however MVM system A activity in vitro (Glazier et al., 1996) and placental expression of glucose transporters GLUT 1 and GLUT 3 (Reid et al., 1999) were unaffected. In the guinea pig, IUGR induced by unilateral artery ligation was associated with decreased transplacental AA transport (Jansson and Persson, 1990). In a sheep model of IUGR induced by maternal hyperthermia and decreased utero-placental blood flow, transplacental transport of leucine (Ross et al., 1996), threonine (Anderson et al., 1997), glucose (Thureen et al., 1992), and ACP (branched-chain AA analog) (de Vrijer et al., 2004) was reduced.

In human IUGR associated with reduced utero-placental blood flow, the activity of several placental AA transporters is reduced whereas placental GLUT1 expression and activity are unaffected (Jansson et al., 1993, 2002b). System A activity is consistently lower in MVM isolated from IUGR placentas (Mahendran et al., 1993; Glazier et al., 1997), especially in preterm IUGR (Jansson et al., 2002b) and is related to the degree of fetal compromise (Glazier et al., 1997). Similarly, the activity of transporters of essential AAs, including system $\beta$ (taurine) and system L (lysine and leucine), is reduced in MVM and/or BM of IUGR placentas (Jansson et al., 1998; Norberg et al., 1998), consistent with the reduced placental transfer of the essential acids leucine and phenylalanine observed in vivo in IUGR pregnancies at term (Paolini et al., 2001). Decreased transplacental AA transport to the fetus may account for the 


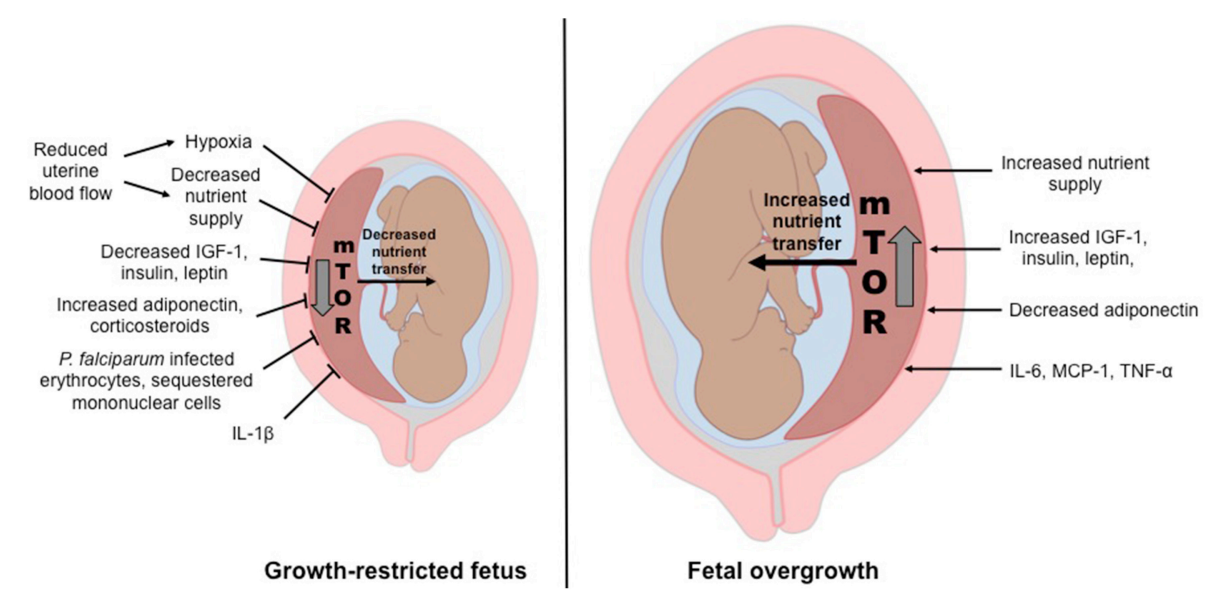

FIGURE 1 | Placental nutrient sensing model. The placenta integrates maternal signals with information from nutrient sensing signaling pathways such as mechanistic target of rapamycin (mTOR) to regulate placental function. As a result, fetal growth is matched to the ability of the maternal supply line to allocate resources to the fetus. Thus, the placental responses to maternal signals influence fetal growth and the long-term health of the offspring.

low plasma levels of certain AAs in growth-restricted fetuses (Economides et al., 1989; Cetin et al., 1990). The activity of lipoprotein lipase (LPL), an enzyme responsible for hydrolysis of lipoproteins, is reduced in MVM of IUGR placentas (Magnusson et al., 2004). IUGR is also associated with a reduced placental expression of lipoprotein receptors, low-density lipoprotein (LDL), and scavenger receptor class B type-I, key receptors for cholesterol uptake from maternal LDL and/or HDL (Wadsack et al., 2007). Thus, placental lipid transport may be impaired in IUGR, possibly contributing to the decreased lipid stores in the IUGR fetus (Padoan et al., 2004). Collectively, these data suggest that the effect of reduced utero-placental blood flow on fetal growth is mediated, in part, by decreased placental nutrient transfer capacity.

\section{Hypoxia}

Despite compensatory mechanisms such as fetal polycythemia, transplacental transfer of oxygen decreases in maternal hypoxia, which typically is associated with IUGR (Giussani et al., 2007). Women residing at high altitude with reduced oxygen tension have higher risk to deliver IUGR babies than women living at sea level (Zamudio and Moore, 2000; Mehta and Mehta, 2008). Nelson and co-workers reported that hypoxia caused a reduced system A transporter expression and activity in cultured primary human trophoblast cells (Nelson et al., 2003), suggesting that adequate oxygen supply is important for the function of nutrient transporters. Furthermore, high altitude hypoxia decreases the expression of GLUT1 in the syncytiotrophoblast plasma membrane (Zamudio et al., 2006).

\section{Maternal Hormones}

Maternal hormones can influence fetal health by altering placental function (Fowden et al., 2015). Maternal IGF-I promotes placental nutrient uptake and transport (SferruzziPerri et al., 2011a). In animal models of IUGR, elevating maternal IGF concentrations improved fetal growth (de Boo et al., 2008).
Acute maternal IGF-I treatment in the late pregnant ewe is associated with enhanced glucose delivery to the fetus (Liu et al., 1994). This was also observed in a mouse model of IUGR where placental glucose transporter expression was increased following intraplacental injection of adenovirus-mediated IGFI (Jones et al., 2013) restoring fetal weights (Keswani et al., 2015). In human trophoblasts, IGF-I increases GLUT1 expression (Baumann et al., 2014) and stimulates glucose and system Amediated AA uptake (Karl, 1995; Roos et al., 2007). Also, reduced maternal circulating IGF-I is associated with smallfor-gestational age and growth-restricted babies (HernandezValencia et al., 2001). IGF-I receptor protein levels were reduced in IUGR (Laviola et al., 2005) and elevated in pregnancies complicated by macrosomia (Jiang et al., 2009).

Insulin and leptin stimulate placental system A activity (Karl et al., 1992; Jansson et al., 2003; von Versen-Hoynck et al., 2009) while adiponectin inhibits insulin-stimulated AA transport (Jones et al., 2010; Rosario et al., 2012; Aye et al., 2014a, 2015). Administration of maternal corticosteroids to pregnant mice during mid-gestation down regulates placental system A transport (Audette et al., 2011) leading to reduced fetal weight (Vaughan et al., 2012). Therefore, maternal hormones influence fetal growth by altering the activity of placental nutrient transporters and placental secretion of hormones (Sferruzzi-Perri et al., 2011a).

\section{Maternal Nutrition}

Fetal growth is greatly influenced by maternal nutrition, and is believed to be mediated, in part, by changes in maternal metabolism and hormone levels.

In a rat model of maternal protein restriction, maternal insulin, IGF-I, and leptin levels were decreased (Rosario et al., 2011) and similar changes were observed in a mouse model of calorie restriction (Sferruzzi-Perri et al., 2011b). Maternal corticosterone levels were also increased in this mouse model (Sferruzzi-Perri et al., 2011b). In contrast, pregnant mice on 
a high fat diet showed increased levels of maternal leptin and decreased adiponectin (Jones et al., 2009b). Consistent with these observations, levels of maternal insulin and leptin were elevated in obese pregnant mice on a high-fat/high-sugar diet (Rosario et al., 2015b).

Maternal endocrine and metabolic changes in response to altered nutrition are similar in experimental models and women. In human IUGR, maternal serum concentrations of IGF-I, insulin, and leptin are decreased (Jansson et al., 2006) while obese pregnant women and pregnancies complicated with gestational diabetes have higher serum levels of leptin, insulin, IGF-I, and decreased levels of adiponectin (Lauszus et al., 2001; Jansson et al., 2008; Aye et al., 2013a, 2015).

Because hormonal regulation of placental nutrient transport is well established, one key mechanism by which maternal nutrition alters placental function and fetal growth could be through modulating placental nutrient transport. Consistent with this hypothesis, various animal experimental models of maternal undernutrition show decreased placental nutrient transport. For example, maternal calorie restriction in the baboon caused IUGR and showed decreased expression and in vitro activity of key AA transporters, decreased in vivo transplacental AA transport as well as lower fetal levels of essential AAs (Kavitha et al., 2014; Pantham et al., 2015b). Calorie restriction in mice resulted in reduced transplacental glucose and leucine transport (Ganguly et al., 2012). In rats, calorie, or protein restriction in late pregnancy decreased neutral AAs and glucose transplacental transport (Rosso, 1977a,b; Malandro et al., 1996; Jansson et al., 2006; Rosario et al., 2012). Therefore, the proposed cause-andeffect link between maternal undernutrition and decreased fetal growth involves the well-established physiological hormonal response to starvation. Specifically, the increase in the levels of catabolic hormones such as cortisol and the decrease in anabolic hormones including insulin and IGF-I are predicted to inhibit placental nutrient transport, resulting in decreased fetal nutrient availability and IUGR. Opposite placental responses have been reported in maternal over-nutrition in association with fetal overgrowth. In a mouse model of maternal obesity, in vitro glucose and AA transporter expression, and activity and in vivo transplacental glucose and AA transport are increased (Aye et al., 2015; Rosario et al., 2015b). Importantly, these findings are consistent with up-regulation of placental AA transport in obese women giving birth to large babies (Jansson et al., 2013) and increased placental capacity to transport AAs and glucose in women with diabetes and fetal overgrowth (Jansson et al., 1999, 2002a).

\section{Inflammatory Mediators}

Altered inflammatory profile in the mother, placenta, or fetus can affect placental function. Specifically, maternal systemic inflammation has been proposed to play a role in the developmental programming of metabolic disorders especially in pregnancies complicated with obesity and gestational diabetes (Ingvorsen et al., 2015; Pantham et al., 2015a). Male offspring of dams injected with lipopolysaccharide during mid-gestation had enhanced food intake, increased body weight and enlarged abdominal adipose tissue with reduced insulin uptake, consistent with development of obesity and insulin resistance (Nilsson et al., 2001). Offspring of dams exposed to high systemic levels of TNF- $\alpha$ or IL- 6 showed increased body weight and adiposity, and exposure to IL-6 alone resulted in insulin resistance in female offspring (Dahlgren et al., 2001).

Maternal obesity in women is associated with a lowgrade systemic maternal inflammation and signs of placental inflammation (Challier et al., 2008) However, levels of circulating MCP-1, IL-6, and C-reactive protein that were elevated in early pregnancy in obese women were comparable to those of normalweight mothers at the end of pregnancy (Ingvorsen et al., 2014) suggesting attenuation of maternal inflammatory state in obese women with advancing gestation. Similarly, women with high BMI had increased circulating levels of MCP-1 and TNF- $\alpha$ and activation of placental inflammatory pathways p38-MAPK and STAT3 (Aye et al., 2014b) without signs of fetal inflammation, suggesting that inflammation associated with maternal overweight/obesity affects the fetus indirectly by modulating placental function.

Maternal circulating cytokines could affect placental function by altering the expression and activity of placental nutrient transporters. IL- 6 and TNF- $\alpha$ have been shown to stimulate system A activity in cultured primary human trophoblasts (Jones et al., 2009a). In contrast, IL-1 $\beta$ decreases system A activity in BeWo cells (Thongsong et al., 2005) and inhibits insulinstimulated system A activity in cultured primary trophoblasts (Aye et al., 2013b). Collectively, these data suggest that a low-grade maternal systemic inflammation in maternal obesity influences fetal growth and programs the fetus for future disease by altering placental functions such as nutrient transport. Whether direct fetal exposure to inflammatory mediators also contributes remains to be established.

\section{Placental Malaria and IUGR}

Every year, $\sim 85$ million pregnant women are at risk of malaria, resulting in $\sim 600,000$ low birth weight deliveries (Steketee et al., 2001; Desai et al., 2007) mainly attributed to IUGR (Guyatt and Snow, 2004). Recent studies suggest that down-regulation of placental nutrient transport may contribute to IUGR associated with malaria (Boeuf et al., 2013; Chandrasiri et al., 2014).

Placental malaria is the sequestration of Plasmodium falciparum-infected erythrocytes in the intervillous space of the placenta (Boeuf et al., 2013). This sequestration can stimulate the recruitment of maternal inflammatory cells such as monocytes and macrophages, a condition termed intervillositis (Ordi et al., 1998) that is associated with an increased risk of low birth weight deliveries (Desai et al., 2007; Rogerson et al., 2007).

Sequestered mononuclear cells and the syncytiotrophoblast can produce various cytokines and chemokines. In placental malaria, intervillous plasma levels of IFN- $\gamma$ and TNF- $\alpha$, IL10, and MCP-1 are increased (Rogerson et al., 2003; Suguitan et al., 2003). Intervillous plasma MIP-1 $\alpha$, IL-8, and monocyteattracting beta-chemokines such as CCL2 and CCL3 are also increased in placental malaria with intervillositis (Abrams et al., 2003; Bouyou-Akotet et al., 2004; Ioannidis et al., 2014). Inflammation could impair placental development and function, contributing to IUGR in placental malaria. Also, decreased 
maternal circulating IGF-I levels were observed in women with placental malaria, especially with intervillositis (Umbers et al., 2011). Maternal leptin levels were reduced in mothers with placental malaria (Kabyemela et al., 2008). Importantly, placental malaria with intervillositis is associated with impaired placental AA uptake (Boeuf et al., 2013) and BM GLUT-1 expression (Chandrasiri et al., 2014). Therefore, inflammation, more so than infection, is associated with reduced placental nutrient transport function and deregulation of maternal hormones, which can impact fetal growth and development. The mechanisms underlying the decreased placental nutrient transport capacity and IUGR in placental malaria remain to be fully established.

\section{mTOR SIGNALING IN PLACENTAL NUTRIENT SENSING}

Mammalian cells have an array of nutrient-sensing signaling pathways, such as AMP-activated protein kinase (AMPK), AA response signal transduction pathway, glycogen synthase-3 (GSK-3), mTOR, and the hexosamine signaling pathway, which regulate cell metabolism in response to altered nutrient levels. Of these, mTOR is believed to play a central role in placental nutrient sensing (Jansson and Powell, 2006; Jansson et al., 2012). mTOR exists as two protein complexes: mTOR Complex 1 (mTORC1) that regulates cell growth, proliferation, and metabolism and mTORC2 that regulates cytoskeletal organization and cellular metabolism. Placental mTOR signaling likely constitutes a critical link between maternal oxygen and nutrient supply and fetal growth (Jansson et al., 2012).

Hypoxia inhibits mTORC1 signaling by increased expression of DNA damage response 1 (REDD1; Brugarolas et al., 2004) and by activation of AMPK (Inoki et al., 2003). Yung and coworkers also reported that placental mTORC1 signaling is inhibited in women residing at high altitude, consistent with the concept that hypoxia inhibits placental mTORC1 signaling (Yung et al., 2008). In addition, the activity of the placental mTOR signaling pathway is influenced by a multitude of upstream regulators such as amino acids, growth factors, and free fatty acids, which are likely to be affected by maternal nutrition. Protein restriction in rats (Jansson et al., 2006) and nutrient restriction in baboons (Kavitha et al., 2014) resulted in inhibition of placental mTORC1 activity, consistent with human IUGR (Roos et al., 2007; Yung et al., 2008; Chen et al., 2015). In contrast, placental mTOR is activated in animal models of maternal obesity (Jones et al., 2009b; Rosario et al., 2015b) and in obese women delivering large babies (Jansson et al., 2013).

mTOR also has a key role in regulating AA transporters in the human placenta. In vitro, mTORC1 positively regulates system A and system L, critical in transplacental AA transport (Rosario et al., 2013). mTORC1 regulates cellular uptake of AAs

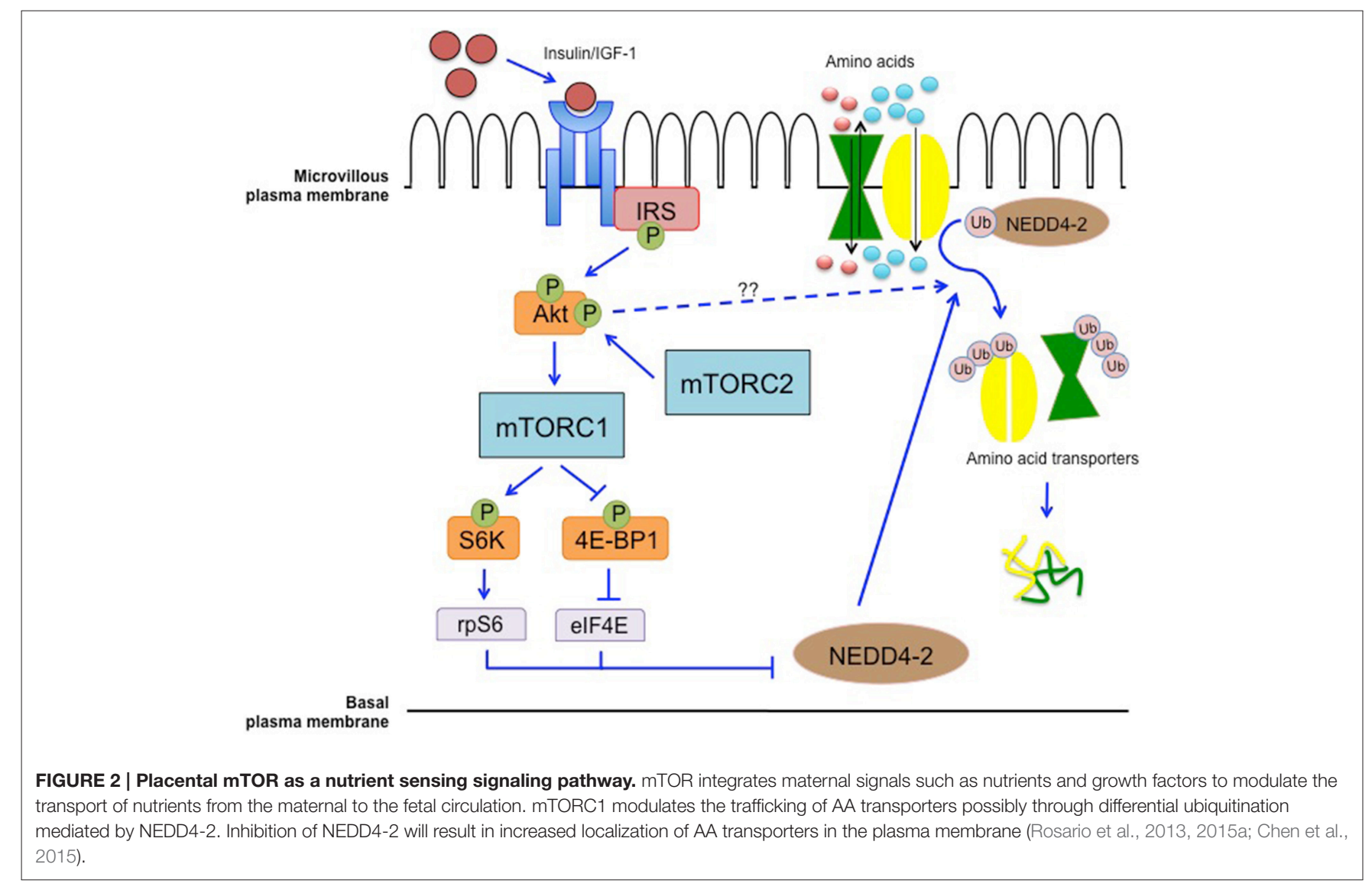


by affecting the plasma membrane trafficking of transporters by differential ubiquitination, possibly through the ubiquitin ligase, NEDD4-2 (Rosario et al., 2013, 2015a; Chen et al., 2015).

We propose that mTOR functions as a key placental nutrient sensing signaling pathway responding to upstream maternal signals by modulating transplacental AA transport and influencing the trafficking of nutrient transporters (Figure 2).

\section{CONCLUSION AND PERSPECTIVES}

Changes in the maternal environment can impair fetal growth and development, which may result in increased susceptibility to diseases in postnatal life. We have proposed that placental nutrient sensing allows the placenta to integrate these perturbations with information from intrinsic nutrient sensing signaling pathways to regulate secretion of hormones and placental nutrient and oxygen transfer. Because fetal nutrient supply programs the fetus for future disease, placental function determines the growth and life-long health of the fetus.

Placental responses to perturbations in the maternal compartment are complex and remain poorly understood, highlighting an urgent need for further well-designed and mechanistic research in this area. Intervention strategies to alleviate pregnancy complications and prevent fetal

\section{REFERENCES}

Abrams, E. T., Brown, H., Chensue, S. W., Turner, G. D., Tadesse, E., Lema, V. M., et al. (2003). Host response to malaria during pregnancy: placental monocyte recruitment is associated with elevated beta chemokine expression. J. Immunol. 170, 2759-2764. doi: 10.4049/jimmunol.170.5.2759

Anderson, A. H., Fennessey, P. V., Meschia, G., Wilkening, R. B., and Battaglia, F. C. (1997). Placental transport of threonine and its utilization in the normal and growth-restricted fetus. Am. J. Physiol. 272, E892-E900.

Armitage, J. A., Khan, I. Y., Taylor, P. D., Nathanielsz, P. W., and Poston, L. (2004). Developmental programming of the metabolic syndrome by maternal nutritional imbalance: how strong is the evidence from experimental models in mammals? J. Physiol. 561, 355-377. doi: 10.1113/jphysiol.2004.072009

Audette, M. C., Challis, J. R., Jones, R. L., Sibley, C. P., and Matthews, S. G. (2011). Antenatal dexamethasone treatment in midgestation reduces system Amediated transport in the late-gestation murine placenta. Endocrinology 152, 3561-3570. doi: 10.1210/en.2011-0104

Aye, I. L., Gao, X., Weintraub, S. T., Jansson, T., and Powell, T. L. (2014a). Adiponectin inhibits insulin function in primary trophoblasts by PPARalpha-mediated ceramide synthesis. Mol. Endocrinol. 28, 512-524. doi: 10.1210/me.2013-1401

Aye, I. L., Lager, S., Ramirez, V. I., Gaccioli, F., Dudley, D. J., Jansson, T., et al. (2014b). Increasing maternal body mass index is associated with systemic inflammation in the mother and the activation of distinct placental inflammatory pathways. Biol. Reprod. 90, 129. doi: 10.1095/biolreprod.113.116186

Aye, I. L. M. H., Jansson, T., and Powell, T. L. (2013b). Interleukin-1 beta inhibits insulin signaling and prevents insulin-stimulated system A amino acid transport in primary human trophoblasts. Mol. Cell. Endocrinol. 381, 46-55. doi: 10.1016/j.mce.2013.07.013

Aye, I. L., Powell, T. L., and Jansson, T. (2013a). Review: adiponectin-the missing link between maternal adiposity, placental transport and fetal growth? Placenta 34(Suppl.), S40-S45. doi: 10.1016/j.placenta.2012.11.024

Aye, I. L., Rosario, F. J., Powell, T. L., and Jansson, T. (2015). Adiponectin supplementation in pregnant mice prevents the adverse effects of maternal programming of adult disease are likely to be most effective if placental function is targeted. mTOR constitutes an important nutrient sensing signaling pathway believed to play a key role in placental nutrient sensing. Maternal obesity with fetal overgrowth is associated with activation of placental mTOR signaling and up-regulation of placental nutrient transport both in animal models (Aye et al., 2015; Rosario et al., 2015a,b) and in women (Jansson et al., 2013). We recently reported that normalization of maternal circulating levels of adiponectin in obese mice completely prevented the activation of placental mTOR signaling, up-regulation of placental nutrient transport and fetal overgrowth (Aye et al., 2015) consistent with the idea that targeting placental mTOR may represent an effective intervention strategy in cases of abnormal fetal growth.

\section{AUTHOR CONTRIBUTIONS}

KD and TJ wrote the paper. PB and TP edited the paper.

\section{FUNDING}

This work was funded by NIH grants HD078376, HD065007, HD68370, R24OD016724, HD021350, and DK089989. obesity on placental function and fetal growth. Proc. Natl. Acad. Sci. U.S.A. 112, 12858-12863. doi: $10.1073 /$ pnas.1515484112

Barker, D. J., Osmond, C., Golding, J., Kuh, D., and Wadsworth, M. E. (1989). Growth in utero, blood pressure in childhood and adult life, and mortality from cardiovascular disease. BMJ 298, 564-567. doi: 10.1136/bmj.298.6673.564

Barker, D. J. P., and Osmond, C. (1986). Infant-mortality, childhood nutrition, and ischemic-heart-disease in England and Wales. Lancet 1, 1077-1081. doi: 10.1016/S0140-6736(86)91340-1

Baumann, M. U., Schneider, H., Malek, A., Palta, V., Surbek, D. V., Sager, R., et al. (2014). Regulation of human trophoblast GLUT1 glucose transporter by insulin-like growth factor I (IGF-I). PLoS ONE 9:e106037. doi: 10.1371/journal.pone.0106037

Boeuf, P., Aitken, E. H., Chandrasiri, U., Chua, C. L., McInerney, B., McQuade, L., et al. (2013). Plasmodium falciparum malaria elicits inflammatory responses that dysregulate placental amino acid transport. PLoS Pathog. 9:e1003153. doi: 10.1371/journal.ppat.1003153

Bouyou-Akotet, M. K., Kombila, M., Kremsner, P. G., and Mavoungou, E. (2004). Cytokine profiles in peripheral, placental and cord blood in pregnant women from an area endemic for Plasmodium falciparum. Eur. Cytokine Netw. 15, $120-125$.

Brugarolas, J., Lei, K., Hurley, R. L., Manning, B. D., Reiling, J. H., Hafen, E., et al. (2004). Regulation of mTOR function in response to hypoxia by REDD1 and the TSC1/TSC2 tumor suppressor complex. Genes Dev. 18, 2893-2904. doi: 10.1101/gad.1256804

Burton, G. J. (2010). The influence of the intrauterine environment on human placental development. J. Reprod. Immunol. 86, 81-82. doi: 10.1016/j.jri.2010.08.006

Cetin, I., Corbetta, C., Sereni, L. P., Marconi, A. M., Bozzetti, P., Pardi, G., et al. (1990). Umbilical amino acid concentrations in normal and growth-retarded fetuses sampled in utero by cordocentesis. Am. J. Obstet. Gynecol. 162, 253-261. doi: 10.1016/0002-9378(90)90860-A

Challier, J. C., Basu, S., Bintein, T., Minium, J., Hotmire, K., Catalano, P. M., et al. (2008). Obesity in pregnancy stimulates macrophage accumulation and inflammation in the placenta. Placenta 29, 274-281. doi: 10.1016/j.placenta.2007.12.010 
Chandrasiri, U. P., Chua, C. L., Umbers, A. J., Chaluluka, E., Glazier, J. D., Rogerson, S. J., et al. (2014). Insight into the pathogenesis of fetal growth restriction in placental malaria: decreased placental glucose transporter isoform 1 expression. J. Infect. Dis. 209, 1663-1667. doi: 10.1093/infdis/jit803

Chen, Y. Y., Rosario, F. J., Shehab, M. A., Powell, T. L., Gupta, M. B., and Jansson, T. (2015). Increased ubiquitination and reduced plasma membrane trafficking of placental amino acid transporter SNAT-2 in human IUGR. Clin. Sci. 129, 1131-1141. doi: 10.1042/CS20150511

Dahlgren, J., Nilsson, C., Jennische, E., Ho, H. P., Eriksson, E., Niklasson, A., et al. (2001). Prenatal cytokine exposure results in obesity and gender-specific programming. Am. J. Physiol. Endocrinol. Metab. 281, E326-E334.

de Boo, H. A., Eremia, S. C., Bloomfield, F. H., Oliver, M. H., and Harding, J. E. (2008). Treatment of intrauterine growth restriction with maternal growth hormone supplementation in sheep. Am. J. Obstet. Gynecol. 199, e551-e559. doi: 10.1016/j.ajog.2008.04.035

Desai, M., ter Kuile, F. O., Nosten, F., McGready, R., Asamoa, K., Brabin, B., et al. (2007). Epidemiology and burden of malaria in pregnancy. Lancet Infect. Dis. 7, 93-104. doi: 10.1016/S1473-3099(07)70021-X

Desoye, G., Hartmann, M., Blaschitz, A., Dohr, G., Hahn, T., Kohnen, G., et al. (1994). Insulin receptors in syncytiotrophoblast and fetal endothelium of human placenta. Immunohistochemical evidence for developmental changes in distribution pattern. Histochemistry 101, 277-285. doi: 10.1007/BF00315915

de Vrijer, B., Regnault, T. R., Wilkening, R. B., Meschia, G., and Battaglia, F. C. (2004). Placental uptake and transport of ACP, a neutral nonmetabolizable amino acid, in an ovine model of fetal growth restriction. Am. J. Physiol. Endocrinol. Metab. 287, E1114-E1124. doi: 10.1152/ajpendo.00259.2004

Díaz, P., Powell, T. L., and Jansson, T. (2014). The role of placental nutrient sensing in maternal-fetal resource allocation. Biol. Reprod. 91, 82. doi: 10.1095/biolreprod.114.121798

Ebenbichler, C. F., Kaser, S., Laimer, M., Wolf, H. J., Patsch, J. R., and Illsley, N. P. (2002). Polar expression and phosphorylation of human leptin receptor isoforms in paired, syncytial, microvillous and basal membranes from human term placenta. Placenta 23, 516-521. doi: 10.1053/plac.2002.0836

Economides, D. L., Nicolaides, K. H., Gahl, W. A., Bernardini, I., and Evans, M. I. (1989). Plasma amino acids in appropriate- and small-for-gestationalage fetuses. Am. J. Obstet. Gynecol. 161, 1219-1227. doi: 10.1016/00029378(89)90670-4

Fang, J., Furesz, T. C., Lurent, R. S., Smith, C. H., and Fant, M. E. (1997). Spatial polarization of insulin-like growth factor receptors on the human syncytiotrophoblast. Pediatr. Res. 41, 258-265. doi: 10.1203/00006450199702000-00017

Forsdahl, A. (1977). Are poor living conditions in childhood and adolescence an important risk factor for arteriosclerotic heart disease? Br. J. Prev. Soc. Med. 31, 91-95. doi: 10.1136/jech.31.2.91

Fowden, A. L., Forhead, A. J., Sferruzzi-Perri, A. N., Burton, G. J., and Vaughan, O. R. (2015). Review: endocrine regulation of placental phenotype. Placenta 36(Suppl. 1), S50-S59. doi: 10.1016/j.placenta.2014.11.018

Gaccioli, F., Lager, S., Powell, T. L., and Jansson, T. (2013). Placental transport in response to altered maternal nutrition. J. Dev. Orig. Health Dis. 4, 101-115. doi: $10.1017 /$ S2040174412000529

Ganguly, A., Collis, L., and Devaskar, S. U. (2012). Placental glucose and amino acid transport in calorie-restricted wild-type and Glut3 null heterozygous mice. Endocrinology 153, 3995-4007. doi: 10.1210/en.2011-1973

Giussani, D. A., Salinas, C. E., Villena, M., and Blanco, C. E. (2007). The role of oxygen in prenatal growth: studies in the chick embryo. J. Physiol. 585, 911-917. doi: 10.1113/jphysiol.2007.141572

Glazier, J. D., Cetin, I., Perugino, G., Ronzoni, S., Grey, A. M., Mahendran, D., et al. (1997). Association between the activity of the system A amino acid transporter in the microvillous plasma membrane of the human placenta and severity of fetal compromise in intrauterine growth restriction. Pediatr. Res. 42, 514-519. doi: 10.1203/00006450-199710000-00016

Glazier, J. D., Sibley, C. P., and Carter, A. M. (1996). Effect of fetal growth restriction on system A amino acid transporter activity in the maternal facing plasma membrane of rat syncytiotrophoblast. Pediatr. Res. 40, 325-329. doi: 10.1203/00006450-199608000-00022

Gluckman, P. D., and Hanson, M. A. (2004). Living with the past: evolution, development, and patterns of disease. Science 305, 1733-1736. doi: $10.1126 /$ science. 1095292
Guyatt, H. L., and Snow, R. W. (2004). Impact of malaria during pregnancy on low birth weight in sub-Saharan Africa. Clin. Microbiol. Rev. 17, 760-769. doi: 10.1128/CMR.17.4.760-769.2004

Hales, C. N., Barker, D. J. P., Clark, P. M. S., Cox, L. J., Fall, C., Osmond, C., et al. (1991). Fetal and infant growth and impaired glucosetolerance at age 64. Br. Med. J. 303, 1019-1022. doi: 10.1136/bmj.303.680 9.1019

Hernandez-Valencia, M., Zarate, A., Ochoa, R., Fonseca, M. E., Amato, D., and De Jesus Ortiz, M. (2001). Insulin-like growth factor I, epidermal growth factor and transforming growth factor beta expression and their association with intrauterine fetal growth retardation, such as development during human pregnancy. Diabetes Obes. Metab. 3, 457-462. doi: 10.1046/j.14631326.2001.00168.x

Holmes, R., Montemagno, R., Jones, J., Preece, M., Rodeck, C., and Soothill, P. (1997). Fetal and maternal plasma insulin-like growth factors and binding proteins in pregnancies with appropriate or retarded fetal growth. Early Hum. Dev. 49, 7-17. doi: 10.1016/S0378-3782(97)01867-7

Ingvorsen, C., Brix, S., Ozanne, S. E., and Hellgren, L. I. (2015). The effect of maternal inflammation on foetal programming of metabolic disease. Acta Physiol. 214, 440-449. doi: 10.1111/apha.12533

Ingvorsen, C., Thysen, A. H., Fernandez-Twinn, D., Nordby, P., Nielsen, K. F., Ozanne, S. E., et al. (2014). Effects of pregnancy on obesity-induced inflammation in a mouse model of fetal programming. Int. J. Obes. 38, 1282-1289. doi: 10.1038/ijo.2014.69

Inoki, K., Zhu, T., and Guan, K. L. (2003). TSC2 mediates cellular energy response to control cell growth and survival. Cell 115, 577-590. doi: 10.1016/S00928674(03)00929-2

Ioannidis, L. J., Nie, C. Q., and Hansen, D. S. (2014). The role of chemokines in severe malaria: more than meets the eye. Parasitology 141, 602-613. doi: $10.1017 /$ S0031182013001984

Jansson, N., Greenwood, S. L., Johansson, B. R., Powell, T. L., and Jansson, T. (2003). Leptin stimulates the activity of the system A amino acid transporter in human placental villous fragments. J. Clin. Endocrinol. Metab. 88, 1205-1211. doi: 10.1210/jc.2002-021332

Jansson, N., Nilsfelt, A., Gellerstedt, M., Wennergren, M., Rossander-Hulthén, L., Powell, T. L., et al. (2008). Maternal hormones linking maternal body mass index and dietary intake to birth weight. Am. J. Clin. Nutr. 87, 1743-1749.

Jansson, N., Pettersson, J., Haafiz, A., Ericsson, A., Palmberg, I., Tranberg, M., et al. (2006). Down-regulation of placental transport of amino acids precedes the development of intrauterine growth restriction in rats fed a low protein diet. J. Physiol. Lond. 576, 935-946. doi: 10.1113/jphysiol.2003.5 50004

Jansson, N., Rosario, F. J., Gaccioli, F., Lager, S., Jones, H. N., Roos, S., et al. (2013). Activation of placental mTOR signaling and amino acid transporters in obese women giving birth to large babies. J. Clin. Endocrinol. Metab. 98, 105-113. doi: $10.1210 /$ jc. $2012-2667$

Jansson, T., Aye, I. L., and Goberdhan, D. C. (2012). The emerging role of mTORC1 signaling in placental nutrient-sensing. Placenta 33(Suppl. 2), e23-e29. doi: 10.1016/j.placenta.2012.05.010

Jansson, T., Ekstrand, Y., Björn, C., Wennergren, M., and Powell, T. L. (2002a). Alterations in the activity of placental amino acid transporters in pregnancies complicated by diabetes. Diabetes 51, 2214-2219. doi: 10.2337/diabetes.51.7.2214

Jansson, T., and Persson, E. (1990). Placental-transfer of glucose and aminoacids in intrauterine growth-retardation - studies with substrate-analogs in the awake guinea-pig. Pediatr. Res. 28, 203-208. doi: 10.1203/00006450199009000-00007

Jansson, T., and Powell, T. L. (2006). Human placental transport in altered fetal growth: does the placenta function as a nutrient sensor? Rev. Placenta 27, S91-S97. doi: 10.1016/j.placenta.2005.11.010

Jansson, T., and Powell, T. L. (2013). Role of placental nutrient sensing in developmental programming. Clin. Obstet. Gynecol. 56, 591-601. doi: 10.1097/GRF.0b013e3182993a2e

Jansson, T., Scholtbach, V., and Powell, T. L. (1998). Placental transport of leucine and lysine is reduced in intrauterine growth restriction. Pediatr. Res. 44, 532-537. doi: 10.1203/00006450-19981000000011 
Jansson, T., Wennergren, M., and Illsley, N. P. (1993). Glucose transporter protein expression in human placenta throughout gestation and in intrauterine growth retardation. J. Clin. Endocrinol. Metab. 77, 1554-1562.

Jansson, T., Wennergren, M., and Powell, T. L. (1999). Placental glucose transport and GLUT 1 expression in insulin-dependent diabetes. Am. J. Obstet. Gynecol. 180, 163-168. doi: 10.1016/S0002-9378(99)70169-9

Jansson, T., Ylvén, K., Wennergren, M., and Powell, T. L. (2002b). Glucose transport and system A activity in syncytiotrophoblast microvillous and basal plasma membranes in intrauterine growth restriction. Placenta 23, 392-399. doi: 10.1053/plac.2002.0826

Jiang, H., Xun, P. C., Luo, G. H., Wang, Q. W., Cai, Y. Q., Zhang, Y. Y., et al. (2009). Levels of insulin-like growth factors and their receptors in placenta in relation to macrosomia. Asia Pac. J. Clin. Nutr. 18, 171-178.

Jones, H. N., Crombleholme, T., and Habli, M. (2013). Adenoviral-mediated placental gene transfer of IGF-1 corrects placental insufficiency via enhanced placental glucose transport mechanisms. PLOS ONE 8:e74632. doi: 10.1371/journal.pone.0074632

Jones, H. N., Jansson, T., and Powell, T. L. (2009a). IL-6 stimulates system A amino acid transporter activity in trophoblast cells through STAT3 and increased expression of SNAT2. Am. J. Physiol. Cell Physiol. 297, C1228-C1235. doi: 10.1152/ajpcell.00195.2009

Jones, H. N., Jansson, T., and Powell, T. L. (2010). Full-length adiponectin attenuates insulin signaling and inhibits insulin-stimulated amino Acid transport in human primary trophoblast cells. Diabetes 59, 1161-1170. doi: $10.2337 / \mathrm{db} 09-0824$

Jones, H. N., Powell, T. L., and Jansson, T. (2007). Regulation of placental nutrient transport-a review. Placenta 28, 763-774. doi: 10.1016/j.placenta.2007.05.002

Jones, H. N., Woollett, L. A., Barbour, N., Prasad, P. D., Powell, T. L., and Jansson, T. (2009b). High-fat diet before and during pregnancy causes marked upregulation of placental nutrient transport and fetal overgrowth in C57/BL6 mice. FASEB J. 23, 271-278. doi: 10.1096/fj.08-116889

Kabyemela, E. R., Muehlenbachs, A., Fried, M., Kurtis, J. D., Mutabingwa, T. K., and Duffy, P. E. (2008). Maternal peripheral blood level of IL-10 as a marker for inflammatory placental malaria. Malar. J. 7:26. doi: 10.1186/1475-2875-7-26

Karl, P. I. (1995). Insulin-like growth factor-1 stimulates amino acid uptake by the cultured human placental trophoblast. J. Cell. Physiol. 165, 83-88. doi: 10.1002/jcp.1041650111

Karl, P. I., Alpy, K. L., and Fisher, S. E. (1992). Amino acid transport by the cultured human placental trophoblast: effect of insulin on AIB transport. Am. J. Physiol. 262, C834-C839.

Kavitha, J. V., Rosario, F. J., Nijland, M. J., McDonald, T. J., Wu, G., Kanai, Y., et al. (2014). Down-regulation of placental mTOR, insulin/IGF-I signaling, and nutrient transporters in response to maternal nutrient restriction in the baboon. FASEB J. 28, 1294-1305. doi: 10.1096/fj.13-242271

Keswani, S. G., Balaji, S., Katz, A. B., King, A., Omar, K., Habli, M., et al. (2015). Intraplacental gene therapy with Ad-IGF-1 corrects naturally occurring rabbit model of intrauterine growth restriction. Hum. Gene Ther. 26, 172-182. doi: 10.1089/hum.2014.065

Krishna, U., and Bhalerao, S. (2011). Placental insufficiency and fetal growth restriction. J. Obstet. Gynaecol. India 61, 505-511. doi: 10.1007/s13224-0110092-x

Lauszus, F. F., Klebe, J. G., and Flyvbjerg, A. (2001). Macrosomia associated with maternal serum insulin-like growth factor-I and -II in diabetic pregnancy. Obstet. Gynecol. 97, 734-741. doi: 10.1016/S0029-7844(01)01189-9

Laviola, L., Perrini, S., Belsanti, G., Natalicchio, A., Montrone, C., Leonardini, A., et al. (2005). Intrauterine growth restriction in humans is associated with abnormalities in placental insulin-like growth factor signaling. Endocrinology 146, 1498-1505. doi: 10.1210/en.2004-1332

Liu, L., Harding, J. E., Evans, P. C., and Gluckman, P. D. (1994). Maternal insulinlike growth factor-I infusion alters feto-placental carbohydrate and protein metabolism in pregnant sheep. Endocrinology 135, 895-900.

Magnusson, A. L., Waterman, I. J., Wennergren, M., Jansson, T., and Powell, T. L. (2004). Triglyceride hydrolase activities and expression of fatty acid binding proteins in the human placenta in pregnancies complicated by intrauterine growth restriction and diabetes. J. Clin. Endocrinol. Metab. 89, 4607-4614. doi: 10.1210/jc.2003-032234

Mahendran, D., Donnai, P., Glazier, J. D., D’Souza, S. W., Boyd, R. D., and Sibley, C. P. (1993). Amino acid (system A) transporter activity in microvillous membrane vesicles from the placentas of appropriate and small for gestational age babies. Pediatr. Res. 34, 661-665. doi: 10.1203/00006450-19931100 0-00019

Malandro, M. S., Beveridge, M. J., Kilberg, M. S., and Novak, D. A. (1996). Effect of low-protein diet-induced intrauterine growth retardation on rat placental amino acid transport. Am. J. Physiol. 271, C295-C303.

Mehta, A. R., and Mehta, P. R. (2008). The hypoxia of high altitude causes restricted fetal growth in chick embryos with the extent of this effect depending on maternal altitudinal status. J. Physiol. 586, 1469-1471. doi: 10.1113/jphysiol.2008.151332

Nelson, D. M., Smith, S. D., Furesz, T. C., Sadovsky, Y., Ganapathy, V., Parvin, C. A., et al. (2003). Hypoxia reduces expression and function of system A amino acid transporters in cultured term human trophoblasts. Am. J. Physiol. Cell Physiol. 284, C310-C315. doi: 10.1152/ajpcell.00253.2002

Nilsson, C., Larsson, B. M., Jennische, E., Eriksson, E., Björntorp, P., York, D. A., et al. (2001). Maternal endotoxemia results in obesity and insulin resistance in adult male offspring. Endocrinology 142, 2622-2630. doi: 10.1210/en.142.6.2622

Nitzan, M., Orloff, S., and Schulman, J. D. (1979). Placental transfer of analogs of glucose and amino acids in experimental intrauterine growth retardation. Pediatr. Res. 13, 100-103. doi: 10.1203/00006450-197902000-00003

Norberg, S., Powell, T. L., and Jansson, T. (1998). Intrauterine growth restriction is associated with a reduced activity of placental taurine transporters. Pediatr. Res. 44, 233-238. doi: 10.1203/00006450-199808000-00016

Ordi, J., Ismail, M. R., Ventura, P. J., Kahigwa, E., Hirt, R., Cardesa, A., et al. (1998). Massive chronic intervillositis of the placenta associated with malaria infection. Am. J. Surg. Pathol. 22, 1006-1011. doi: 10.1097/00000478-199808000-00011

Padoan, A., Rigano, S., Ferrazzi, E., Beaty, B. L., Battaglia, F. C., and Galan, H. L. (2004). Differences in fat and lean mass proportions in normal and growth-restricted fetuses. Am. J. Obstet. Gynecol. 191, 1459-1464. doi: 10.1016/j.ajog.2004.06.045

Pantham, P., Aye, I. L., and Powell, T. L. (2015a). Inflammation in maternal obesity and gestational diabetes mellitus. Placenta 36, 709-715. doi: 10.1016/j.placenta.2015.04.006

Pantham, P., Rosario, F. J., Njiland, M., Cheung, A., Nathanielsz, P. W., Powell, T. L., et al. (2015b). Reduced placental amino acid transport in response to maternal nutrient restriction in the baboon. Am. J. Physiol. Regul. Integr. Comp. Physiol. 309, R740-R746. doi: 10.1152/ajpregu.00161.2015

Paolini, C. L., Marconi, A. M., Ronzoni, S., Di Noio, M., Fennessey, P. V., Pardi, G., et al. (2001). Placental transport of leucine, phenylalanine, glycine, and proline in intrauterine growth-restricted pregnancies. J. Clin. Endocrinol. Metab. 86, 5427-5432. doi: 10.1210/jcem.86.11.8036

Ravelli, A. C. J., van der Meulen, J. H. P., Michels, R. P. J., Osmond, C., Barker, D. J. P., Hales, C. N., et al. (1998). Glucose tolerance in adults after prenatal exposure to famine. Lancet 351, 173-177. doi: 10.1016/S0140-6736(97)07244-9

Reid, G. J., Lane, R. H., Flozak, A. S., and Simmons, R. A. (1999). Placental expression of glucose transporter proteins 1 and 3 in growth-restricted fetal rats. Am. J. Obstet. Gynecol. 180, 1017-1023. doi: 10.1016/S00029378(99)70675-7

Rogerson, S. J., Brown, H. C., Pollina, E., Abrams, E. T., Tadesse, E., Lema, V. M., et al. (2003). Placental tumor necrosis factor alpha but not gamma interferon is associated with placental malaria and low birth weight in Malawian women. Infect. Immun. 71, 267-270. doi: 10.1128/IAI.71.1.267-270.2003

Rogerson, S. J., Hviid, L., Duffy, P. E., Leke, R. F., and Taylor, D. W. (2007). Malaria in pregnancy: pathogenesis and immunity. Lancet Infect. Dis. 7, 105-117. doi: 10.1016/S1473-3099(07)70022-1

Roos, S., Jansson, N., Palmberg, I., Säljö, K., Powell, T. L., and Jansson, T. (2007). Mammalian target of rapamycin in the human placenta regulates leucine transport and is down-regulated in restricted fetal growth. J. Physiol. 582, 449-459. doi: 10.1113/jphysiol.2007.129676

Roos, S., Kanai, Y., Prasad, P. D., Powell, T. L., and Jansson, T. (2009). Regulation of placental amino acid transporter activity by mammalian target of rapamycin. Am. J. Physiol. Cell Physiol. 296, C142-C150. doi: 10.1152/ajpcell.00330.2008

Rosario, F. J., Dimasuay, K. G., Kanai, Y., Powell, T. L., and Jansson, T. (2015a). Regulation of amino acid transporter trafficking by mTORC1 in primary human trophoblast cells is mediated by the ubiquitin ligase Nedd4-2. Clin Sci (Lond). doi: 10.1042/CS20150554. [Epub ahead of print].

Rosario, F. J., Jansson, N., Kanai, Y., Prasad, P. D., Powell, T. L., and Jansson, T. (2011). Maternal protein restriction in the rat inhibits placental insulin, mTOR, 
and STAT3 signaling and down-regulates placental amino acid transporters. Endocrinology 152, 1119-1129. doi: 10.1210/en.2010-1153

Rosario, F. J., Kanai, Y., Powell, T. L., and Jansson, T. (2013). Mammalian target of rapamycin signalling modulates amino acid uptake by regulating transporter cell surface abundance in primary human trophoblast cells. J. Physiol. 591, 609-625. doi: 10.1113/jphysiol.2012.238014

Rosario, F. J., Kanai, Y., Powell, T. L., and Jansson, T. (2015b). Increased placental nutrient transport in a novel mouse model of maternal obesity with fetal overgrowth. Obesity 23, 1663-1670. doi: 10.1002/oby.21165

Rosario, F. J., Schumacher, M. A., Jiang, J., Kanai, Y., Powell, T. L., and Jansson, T. (2012). Chronic maternal infusion of full-length adiponectin in pregnant mice down-regulates placental amino acid transporter activity and expression and decreases fetal growth. J. Physiol. (Lond). 590, 1495-1509. doi: 10.1113/jphysiol.2011.226399

Ross, J. C., Fennessey, P. V., Wilkening, R. B., Battaglia, F. C., and Meschia, G. (1996). Placental transport and fetal utilization of leucine in a model of fetal growth retardation. Am. J. Physiol. 270, E491-E503.

Rosso, P. (1977a). Maternal-fetal exchange during protein malnutrition in the rat. Placental transfer of alpha-amino isobutyric acid. J. Nutr. 107, 2002-2005.

Rosso, P. (1977b). Maternal-fetal exchange during protein malnutrition in the rat. Placental transfer of glucose and a nonmetabolizable glucose analog. J. Nutr. 107, 20006-20010.

Sferruzzi-Perri, A. N., Owens, J. A., Pringle, K. G., and Roberts, C. T. (2011a). The neglected role of insulin-like growth factors in the maternal circulation regulating fetal growth. J. Physiol. (Lond). 589, 7-20. doi: 10.1113/jphysiol.2010.198622

Sferruzzi-Perri, A. N., Vaughan, O. R., Coan, P. M., Suciu, M. C., Darbyshire, R., Constancia, M., et al. (2011b). Placental-specific Igf2 deficiency alters developmental adaptations to undernutrition in mice. Endocrinology 152, 3202-3212. doi: 10.1210/en.2011-0240

Steketee, R. W., Nahlen, B. L., Parise, M. E., and Menendez, C. (2001). The burden of malaria in pregnancy in malaria-endemic areas. Am. J. Trop. Med. Hyg. 64, 28-35.

Suguitan, A. L. Jr., Leke, R. G., Fouda, G., Zhou, A., Thuita, L., Metenou, S., et al. (2003). Changes in the levels of chemokines and cytokines in the placentas of women with Plasmodium falciparum malaria. J. Infect. Dis. 188, 1074-1082. doi: $10.1086 / 378500$

Thongsong, B., Subramanian, R. K., Ganapathy, V., and Prasad, P. D. (2005). Inhibition of amino acid transport system a by interleukin1 beta in trophoblasts. J. Soc. Gynecol. Investig. 12, 495-503. doi: 10.1016/j.jsgi.2005.06.008
Thureen, P. J., Trembler, K. A., Meschia, G., Makowski, E. L., and Wilkening, R. B. (1992). Placental glucose transport in heat-induced fetal growth retardation. Am. J. Physiol. 263, R578-R585.

Umbers, A. J., Boeuf, P., Clapham, C., Stanisic, D. I., Baiwog, F., Mueller, I., et al. (2011). Placental malaria-associated inflammation disturbs the insulinlike growth factor axis of fetal growth regulation. J. Infect. Dis. 203, 561-569. doi: 10.1093/infdis/jiq080

Vaughan, O. R., Sferruzzi-Perri, A. N., and Fowden, A. L. (2012). Maternal corticosterone regulates nutrient allocation to fetal growth in mice. J. Physiol. (Lond). 590, 5529-5540. doi: 10.1113/jphysiol.2012.239426

von Versen-Höynck, F., Rajakumar, A., Parrott, M. S., and Powers, R. W. (2009). Leptin affects system A amino acid transport activity in the human placenta: evidence for STAT3 dependent mechanisms. Placenta 30, 361-367. doi: 10.1016/j.placenta.2009.01.004

Wadsack, C., Tabano, S., Maier, A., Hiden, U., Alvino, G., Cozzi, V., et al. (2007). Intrauterine growth restriction is associated with alterations in placental lipoprotein receptors and maternal lipoprotein composition. Am. J. Physiol. Endocrinol. Metab. 292, E476-E484. doi: 10.1152/ajpendo.00547.2005

Yildiz, L., Avci, B., and Ingeç, M. (2002). Umbilical cord and maternal blood leptin concentrations in intrauterine growth retardation. Clin. Chem. Lab. Med. 40, 1114-1117. doi: 10.1515/cclm.2002.195

Yung, H. W., Calabrese, S., Hynx, D., Hemmings, B. A., Cetin, I., Charnock-Jones, D. S., et al. (2008). Evidence of placental translation inhibition and endoplasmic reticulum stress in the etiology of human intrauterine growth restriction. Am. J. Pathol. 173, 451-462. doi: 10.2353/ajpath.2008.071193

Zamudio, S., Baumann, M. U., and Illsley, N. P. (2006). Effects of chronic hypoxia in vivo on the expression of human placental glucose transporters. Placenta 27, 49-55. doi: 10.1016/j.placenta.2004.12.010

Zamudio, S., and Moore, L. G. (2000). Altitude and fetal growth: current knowledge and future directions. Ultrasound Obstet. Gynecol. 16, 6-8. doi: 10.1046/j.1469-0705.2000.00155.x

Conflict of Interest Statement: The authors declare that the research was conducted in the absence of any commercial or financial relationships that could be construed as a potential conflict of interest.

Copyright (c) 2016 Dimasuay, Boeuf, Powell and Jansson. This is an open-access article distributed under the terms of the Creative Commons Attribution License (CC $B Y)$. The use, distribution or reproduction in other forums is permitted, provided the original author(s) or licensor are credited and that the original publication in this journal is cited, in accordance with accepted academic practice. No use, distribution or reproduction is permitted which does not comply with these terms. 